\title{
Effect of Stacking Sequence on the Flexural Properties of Carbon and Glass Fibre Reinforced Hybrid Composites
}

\author{
Chensong Dong ${ }^{*}{ }^{1}$, Ian J. Davies ${ }^{1}$ \\ ${ }^{1}$ Department of Mechanical Engineering, Curtin University, GPO Box U1987, Perth, WA 6845,
} Australia

\begin{abstract}
A study on the flexural properties of carbon and glass fibre reinforced epoxy hybrid composites is presented in this paper. For the purpose of understanding the effect of stacking sequence on the flexural properties, test specimens of both glass/carbon and sandwich stacking sequences were studied both experimentally and by simulation. The experimental flexural properties were obtained by three-point bend test in accordance with ASTM D7264/D7264M-15. Simulation was achieved with the aid of Finite Element Analysis (FEA) and Classical Lamination Theory (CLT). From the experimental and simulation results, it is concluded that for the hybrid composites with glass/carbon stacking sequences, when glass/epoxy laminas are placed on the compressive face, positive hybrid effects are present. When glass/epoxy laminas are placed on the tensile face, the hybrid effect is dominantly negative. For the sandwich type hybrid composites, carbon/epoxy laminas should be the skin and glass/epoxy laminas should be the core.
\end{abstract}

Keywords: Composites; Hybrid; Flexural; Carbon; Glass

\section{Introduction}

Fibre reinforced hybrid composites are composites containing more than one fibre type. Hybrid composites may be designed in various configurations: intra-ply, inter-ply, sandwich and intimately

\footnotetext{
* Corresponding author. Tel: +61 (8) 92669204; fax: +61 (8) 92662681; email: c.dong@ curtin.edu.au.
} 
mixed [1]. In a fibre reinforced hybrid composite, usually one fibre type is low elongation e.g. carbon while the other is high elongation e.g. glass. The introduction of high elongation fibres could enhance the strain-to-failure [2], and may improve the strength.

When evaluating the mechanical properties of hybrid composites, a general rule of mixtures (RoM) approach, which quantifies a material property with respect to the constituent properties and the volume concentration, is often utilized. However, it was found from a number of studies [1, 3-5] that the material property as predicted by the RoM differed from what was observed in reality. The difference between the property and the RoM is called hybrid effect. A positive or negative hybrid effect is defined as a positive or negative deviation of a certain mechanical property from the RoM behaviour, respectively [6].

It is shown from the literature that both thermoset and thermoplastic matrix hybrid composites have been developed. The most common hybrid composite is the carbon/glass fibre reinforced thermoset hybrid composite. Unidirectional continuous carbon/glass fibre reinforced hybrid composites have been extensively studied [2-4, 7-12]. An early study [13] suggested that the tensile, flexural and compressive strengths and the tensile modulus showed no hybrid effects. However, it was later shown $[3,4,8]$ positive hybrid effects existed for the flexural strength of unidirectional carbon/glass fibre reinforced hybrid composites. In addition to unidirectional continuous fibre hybrid composites, Dong and Davies [11] found the flexural strength of bidirectional carbon and glass fibre reinforced hybrid composites agreed with the RoM. Pandya et al. [14] reported that both the tensile and compressive strengths of carbon and glass woven fabric hybrid composites showed positive hybrid effects. Giancaspro et al. [15] reported improved flexural properties of carbon and glass woven fabric hybrid composites. Muñoz et al. [16] studied the tensile behaviour of 3D woven hybrid composites containing carbon and glass fibres, and showed that the full contribution of the glass fibres to the composite strength was not employed but their presence increased the fracture strain and the energy dissipated during fracture. Yu et al. [17] showed pseudo-ductility could be achieved for intermingled highly aligned short carbon/glass fibre hybrid composites. Miwa and 
Horiba [18] found that the tensile strength of random short carbon/glass fibre hybrid composites could be estimated by the additive rule of hybrid mixtures.

Besides carbon/glass fibre reinforced hybrid composites, hybrid composites reinforced by other fibre types, e.g. carbon/E glass fibre fabrics [19], carbon/basalt fibre fabrics [19], glass/Kevlar fabrics [20] and carbon/basalt fibres [21]. Some studies showed potential existence of hybrid effects. For example, Ary Subajia et al. [21] showed higher flexural strength and modulus were obtained when carbon fibre layer was stacked at the compressive face (outer layer).

In addition to thermoset matrix hybrid composites, thermoplastic hybrid composites e.g. carbon and self-reinforced polypropylene (SRPP) fibre hybrid composites have also been studied [22, 23]. It was shown that intralayer hybrids of SRPP and CFPP were able to combine the high stiffness and high strength of carbon fibre composites, without losing the ductility of the SRPP [22].

It is shown that the strength of a composite is strongly dependent on its stacking sequence [24, 25]. For unidirectional continuous carbon/glass fibre reinforced hybrid composites under flexural loading, it was shown that partial substitution of glass fibres for carbon fibres on the compressive face resulted in improved flexural strength, i.e. positive hybrid effect. Dong et al. [7, 9, 10] further investigated optimal design of hybrid composites, and concluded that the fibre volume fraction of the glass/epoxy section needed to be higher than that of the carbon/epoxy section in order to achieve positive hybrid effects [7, 9]. Kalantari et al. [26] investigated the influence of stacking sequence on the flexural strength of carbon/glass fibre reinforced hybrid composites and concluded that a positive hybrid effect could be achieved for both unidirectional and bidirectional carbon/glass fibre reinforced epoxy hybrid composites.

Although positive hybrid effects exist for the flexural properties when high elongation fibres e.g. glass are placed on the compressive face, this results in asymmetric laminates. This problem can be avoided by utilising a sandwich structure. Jalalvand et al. [27] numerically studied the tensile behaviour of unidirectional carbon and glass fibre reinforced sandwich composites. Zhang et al. 
[28] studied the tensile, compressive and flexural behaviours of E glass and T300 carbon woven fabric reinforced hybrid sandwich composites.

In this study, the effect of stacking sequence on the hybrid effect was investigated. Both glass/carbon and sandwich stacking sequences were studied. For the glass/carbon stacking sequences, substitution of glass fibres occurred on both the compressive and tensile faces. One type of glass fibres (E glass) and two types of carbon fibres (IM-7 and TR50S) were chosen. Threepoint bend test was conducted in accordance with ASTM D7264/D7264M-15 for all the test specimens. In addition, the flexural properties were obtained by simulation with the aid of Finite Element Analysis (FEA) and Classical Lamination Theory (CLT) modelling.

\section{Experiments}

\subsection{Three-Point Bend Test}

In this study, three-point bend test was conducted on an Instron 550R universal testing machine in accordance to procedure A of ASTM D7264/D7264M-15 to determine the flexural properties of composites. The schematic drawing of three-point bend test is shown in Figure 1, where $L$ is the span and $h$ is the depth.

\section{Insert Figure 1}

\section{Figure 1: Schematic drawing of three-point bend test}

The test specimens were made in house by the hand lay-up process. One type of glass fibres, E glass and two types of carbon fibres, IM-7 and TR50S, were employed to reinforce an epoxy resin. Epoxy resins are widely used in composites because of their high strength (tensile, compressive and flexural), good chemical resistance, fatigue resistance, corrosion resistance and electrical resistance [29]. The details and selected properties of the fibres and epoxy resin are presented in Table 1. 
Table 1: Selected properties of fibres and resin $[12,30]$

\begin{tabular}{lccc}
\hline \multicolumn{1}{c}{ Material } & $\begin{array}{c}\text { Longitudinal } \\
\text { tensile } \\
\text { modulus (GPa) }\end{array}$ & $\begin{array}{c}\text { Longitudinal } \\
\text { tensile strength } \\
(\mathbf{M P a})\end{array}$ & $\begin{array}{c}\text { Density } \\
\left(\mathbf{g} / \mathbf{c m}^{\mathbf{3}}\right)\end{array}$ \\
\hline $\begin{array}{l}\text { HexTow High Strength Carbon } \\
\begin{array}{l}\text { Fibre IM-7 5000 } \\
\text { (Hexcel, Stamford, CT, USA) }\end{array}\end{array}$ & 301 & 5310 & 1.8 \\
$\begin{array}{l}\text { Pyrofil TR50S 12K carbon fibre } \\
\text { (Grafil Inc, Sacramento, CA, USA) }\end{array}$ & 240 & 4900 & 1.82 \\
$\begin{array}{l}\text { E glass SE 2350 type 30 single-end } \\
\text { continuous glass fibre roving } \\
\text { (Owens Corning, Toledo, OH }\end{array}$ & & & \\
$\begin{array}{l}\text { 43659, USA) } \\
\text { Kinetix R240 high performance } \\
\text { epoxy resin } \\
\text { (ATL Composites Pty Ltd, }\end{array}$ & 72 & 3450 & 2.58 \\
Australia) & & & \\
\hline
\end{tabular}

The stacking sequences being investigated in this study, including a 6-ply full carbon, a 5-ply full glass and eight hybrid sequences, are shown in Figure 2. For composites produced using autoclave curing, the processing conditions during manufacture greatly influence the resulting mechanical properties. Owing to the simplicity, the process parameters were optimised by adopting a heuristic approach [31, 32]. Carbon and glass fibre/epoxy prepregs were cut into sections of approximate size $300 \mathrm{~mm} \times 50 \mathrm{~mm}$ and then stacked into a unidirectional plate according to the stacking sequence. The resulting prepreg plates were cured under vacuum in an autoclave at $120{ }^{\circ} \mathrm{C}$ (as recommended by the matrix resin manufacturer) with compressive pressure $1 \mathrm{MPa}$ and holding time $30 \mathrm{~min}$ being utilised. The thickness of test specimens was between $2 \mathrm{~mm}$ to $3 \mathrm{~mm}$; and the width was around 13 mm. Three span-to-depth ratios, 16, 32 and 64, were chosen. The crosshead speed was 1.0 $\mathrm{mm} / \mathrm{min}$ according to ASTM D7264/D7264M-15. A photo of three-point bend test is shown in Figure 3. 


\section{Insert Figure 2}

\section{Figure 2: Stacking sequences with top laminas subjected to compression}

A minimum of 5 tests were conducted for each stacking sequence, and the average values and variations were determined and recorded. Following the testing, the test specimens were also inspected via optical microscopy to observe the failure mode and identify the failure mechanism.

For a specimen in three point bend test, the flexural strength $\left(S_{F}\right)$, modulus $\left(E_{F}\right)$ and strain-to-failure $\left(\varepsilon_{F}\right)$ are given by [33]:

$$
\begin{aligned}
& S_{F}=\frac{3 P_{\max } L}{2 b h^{2}} \\
& \varepsilon_{F}=\frac{6 D h}{L^{2}} \\
& E_{F}=\frac{\Delta \sigma_{F}}{\Delta \epsilon_{F}}
\end{aligned}
$$

where $L, b$ and $h$ are the span, width and depth of the specimen, $D$ is the maximum deflection before failure, $P_{\max }$ is the maximum load encountered before failure, and $\sigma_{F}$ is the flexural stress.

\section{Insert Figure 3}

\section{Figure 3: Three-point bend test}

For the purpose of characterising the degree of hybridisation, the volume fraction of the glass fibres in all fibres is called the hybrid ratio, i.e.

$$
r_{h}=\frac{h_{g} V_{f g}}{h_{g} V_{f g}+h_{c} V_{f c}}
$$

where $h_{c}$ and $h_{g}$ are the thicknesses of the carbon/epoxy and glass/epoxy sections, respectively, and $V_{f c}$ and $V_{f g}$ are the fibre volume fractions of the carbon/epoxy and glass/epoxy sections, 
respectively. It is shown from Eqn. 4 that $r_{h}=0$ for the full carbon fibre composites and $r_{h}=1$ for the full glass fibre composites, respectively.

The flexural strength of a hybrid composite according to the RoM is given by $S_{F R o M}=$ $S_{F c}\left(1-r_{h}\right)+S_{F g} r_{h}$, where $S_{F c}$ and $S_{F g}$ are the flexural strengths of full carbon fibre composite and full glass fibre composite, respectively. The hybrid effect is given by $e_{h}=S_{F} / S_{F R o M}-1$.

\subsection{Stress-Strain Curves}

When the span-to-depth ratio is 64 , the stress-strain curves for the composites reinforced by IM-7 and E glass fibres are shown in Figure 4. It is shown from these curves that in general, the strain-tofailure increases with the content of glass fibres. When the strain is greater than 0.015 , the slope starts to decrease because of yield of the matrix. The failure stress of the hybrid configurations is slightly lower than that of the full carbon one, and the full glass configuration has the lowest failure stress. For span-to-depth ratios 16 and 32, similar trends were found but the specimens failed at lower flexural stresses compared to span-to-depth ratio 64. The increase of the flexural strength with span-to-depth ratio is due to the reduced effect of shear stresses (when compared to axial stresses) [12]. When glass/epoxy laminas were placed on the tensile face, it was also shown the strain-to-failure increased with the content of glass fibres, but the hybrid specimens failed at lower flexural stresses. No significant differences were noticed between IM-7 carbon/E glass and TR50S/E glass carbon composite specimens.

Insert Figure 4

Figure 4: Stress-strain curves from bend test at span-to-depth ratio 64 for composites reinforced by $\mathrm{E}$ glass and IM-7 fibres when $\mathrm{E}$ glass fibres are placed on the compressive face: (a) $\left[0_{6 \mathrm{C}}\right] ;(\mathrm{b})\left[0_{\mathrm{G}} / \mathbf{0}_{4 \mathrm{C}}\right] ;(\mathrm{c})\left[0_{2 \mathrm{G}} / \mathbf{0}_{3 \mathrm{C}}\right] ;(\mathrm{d})\left[0_{5 \mathrm{G}}\right]$ 


\subsection{Failure Modes}

The failed test specimens were observed via optical microscopy to uncover the failure mechanism. It was found that failure mostly occurred on the compressive face, because the compressive strength was significantly lower than the tensile strength for both carbon and glass fibre composites. This is in agreement with previous findings [21]. The compressive faces of the failed specimens of different stacking sequences are shown in Figure 5. When glass/epoxy laminas were placed on the compressive face, the dominant failure mode was kinking (highly localised fibre buckling [14]) and microbuckling. When carbon/epoxy laminas were placed on the compressive face, failure was also found on the compressive face, and the flexural strength was significantly lower because carbon fibre composites had lower compressive strain-to-failure compared to glass fibre composites. Since failure occurs on the compressive face, utilising high elongation material, e.g. glass/epoxy, could enhance the strain to failure and thus improve the flexural strength. On the other hand, if a hybrid composite is in tension, failure will occur at the low elongation material, e.g. carbon/epoxy, and followed by delamination [34].

According to the Hertzian contact stress model, the maximum contact stress is typically $5 \%$ of the longitudinal in-plane stress when the span-to-depth ratio is 64 (which is a typical span-to-depth ratio for high performance unidirectional polymer matrix composites). Thus, the contact stress has negligible effect, which is in good agreement with previous experimental study by the present authors $[3,4,12]$.

Insert Figure 5

Figure 5: Compressive faces of failed IM-7/E glass/epoxy composite specimens at 5x magnification: (a) [06c]; (b) $\left[0_{G} / 0_{4 C}\right] ;(c)\left[0_{2 G} / 0_{3 C}\right] ;(d)\left[0_{2 G} / 0_{2 C}\right] ;(e)\left[0_{3 G} / 0_{C}\right] ;$ (f) $\left[0_{5 G}\right]$ 


\subsection{Flexural Modulus and Strength}

The flexural moduli of the IM-7/E glass hybrid composites at various span-to-depth ratios are shown in Figures 6 and 7, respectively. It is shown that both the flexural modulus and strength increase with the span-to-depth ratio.

\section{Insert Figure 6}

Figure 6: Flexural moduli of IM-7/E glass hybrid composites at various span-to-depth ratios. Left: glass/epoxy laminas placed on the compressive face; right: glass/epoxy laminas placed on the tensile face

\section{Insert Figure 7}

Figure 7: Flexural strengths of IM-7/E glass hybrid composites at various span-to-depth ratios. Left: glass/epoxy laminas placed on the compressive face; right: glass/epoxy laminas placed on the tensile face

\section{Modelling}

\subsection{Model Development}

In order to explain the experimental findings, the flexural properties of hybrid composites were studied numerically by FEA using a commercial software package ANSYS Mechanical APDL. The details of FEA can be found in our previous studies [4, 7], and a brief introduction is given here. A composite specimen was represented by a 2D model consisting of a number of laminas and PLANE182 element was used to model each lamina. The average thicknesses and fibre volume fractions of carbon/epoxy and glass/epoxy laminas were determined from the test specimens. For example, the lamina thicknesses of the IM-7/epoxy and E glass/epoxy laminas were $0.4 \mathrm{~mm}$ and $0.63 \mathrm{~mm}$, respectively, and the fibre volume fractions of the IM-7/epoxy and E glass/epoxy laminas were $34.5 \%$ and $48 \%$, respectively. For each lamina, based on the constituent properties and its fibre volume fraction, the lamina properties, including the longitudinal modulus $E_{11}$ and the shear moduli $G_{12}, G_{13}$ and $G_{23}$, were derived by Hashin's model [35]. The transverse moduli $E_{22}$ and $E_{33}$ 
were derived from the stress-strain relationship [36]. Material models were then created using the lamina properties.

Two modelling techniques were employed in this study. Linear elastic analysis was employed for determining the flexural modulus. A bending load, $P$, was applied and the corresponding deflection was obtained. The flexural modulus was then obtained by Eqn. 3 .

Nonlinear large displacement analysis was utilised for determining the flexural strength. The load $P$ was increased and the stresses on the compressive faces of both the glass/epoxy and the carbon/epoxy sections were examined. The maximum load, $P_{\max }$, was determined when any stress reached the corresponding compressive strength, and the flexural strength was calculated according to Eqn. 1. The compressive strength was determined with the assumption of the microbuckling or kinking mode. Lo-Chim model [37] or Budiansky model [38], can be used to predict the compressive strength of a lamina. Lo-Chim model is given by:

$$
S_{C}=\frac{G_{12}}{1.5+12(6 / \pi)^{2}\left(G_{12} / E_{11}\right)}
$$

where $S_{C}$ is compressive strength, and $G_{12}$ and $E_{11}$ are shear and tensile moduli, respectively.

Budiansky model is given by:

$$
S_{C}=\frac{G_{m}}{\left(1-V_{f}\right)\left(1+\phi / \gamma_{Y}\right)}
$$

where $\gamma_{Y}$ is the longitudinal shear yield strain of composite and $\phi$ is the initial misalignment angle.

Because the stress distribution is uniform in compression but non-uniform in bending, from Weibull statistical theory [39], the relationship between the flexural strength and compressive strength can be given by

$$
\frac{S_{F}}{S_{C}}=\left[2(m+1)^{2} \frac{V_{C}}{V_{F}}\right]^{\frac{1}{m}}
$$


where $m$ is the flaw density exponent that determines the scatter of strength for the material, and $V_{C}$ and $V_{F}$ are the volumes of the specimens being stressed. It is shown that the flexural strength is about $30 \%$ higher than the compressive strength.

The flexural properties were also obtained analytically by CLT [30]. The load was increased until one of the maximum compressive stresses reached the compressive strength $[3,4]$. The flexural strength was calculated according to Eqn. 1. The deflection at the mid-span was obtained from the curvature, and the flexural modulus was calculated according to Eqns.1-3.

\subsection{Flexural Modulus}

At span-to-depth ratio $L / h=64$, the flexural moduli of the IM-7/E glass and TR50S/E glass hybrid composites from the experiments, FEA and CLT are shown in Figures 8 and 9, respectively. It is shown that FEA and CLT predictions are in good agreement with the experimental results.

\section{Insert Figure 8}

Figure 8: Flexural moduli from experiments, FEA, and CLT for composites reinforced by IM-7 carbon and E glass fibres. Left: glass/epoxy laminas placed on the compressive face; right: glass/epoxy laminas placed on the tensile face

\section{Insert Figure 9}

Figure 9: Flexural moduli from experiments, FEA, and CLT for composites reinforced by TR50S carbon and E glass fibres. Left: glass/epoxy laminas placed on the compressive face; right: glass/epoxy laminas placed on the tensile face

Owing to the lower stiffness of glass fibres compared to carbon fibres, substitution of glass/epoxy laminas for carbon/epoxy laminas decreases the flexural modulus. No significant differences are shown when glass fibres are placed on the compressive face or tensile face. When the substitution occurs around the mid-plane, the flexural modulus shows little change [26]. 
In addition to carbon/glass stacking sequences, the hybrid sandwich composites reinforced by $\mathrm{E}$ glass and T300 carbon woven fabrics from a previous study [28] were modelled using the same approach. The core was E glass laminas and both skins were T300 carbon laminas. Four stacking sequences, $[\mathrm{G}]_{8},\left[\mathrm{C}_{1} \mathrm{G}_{3}\right]_{\mathrm{S}},\left[\mathrm{C}_{2} \mathrm{G}_{2}\right]_{\mathrm{S}}$ and $[\mathrm{C}]_{8}$, were studied, where $\mathrm{G}$ and $\mathrm{C}$ denote $\mathrm{E}$ glass and $\mathrm{T} 300$ carbon laminas respectively. The flexural moduli from the experiments and FEA are shown in Figure 10. Owing to the higher stiffness of carbon fibres compared to glass fibres, substitution of carbon/epoxy laminas for glass/epoxy laminas increases the flexural modulus.

\title{
Insert Figure 10
}

Figure 10: Flexural moduli of the hybrid sandwich composites reinforced by $E$ glass and $T 300$ carbon woven fabrics

\subsection{Flexural Strength}

The flexural strengths of the IM-7/E glass and TR50S/E glass hybrid composites from the experiments, FEA and CLT are shown in Figures 11 and 12. It is seen that both the FEA predictions and CLT calculations are in good agreement with the experimental results. When the glass fibres are placed on the compressive face, some hybrid configurations e.g. $\left[0_{\mathrm{G}} 0_{4 \mathrm{C}}\right]$ exhibit improved flexural strength compared to the full carbon composite. This is in agreement with our previous studies on unidirectional hybrid composites [7,9]. However, if the loading direction is reversed, i.e. the glass fibres are placed on the tensile face, the flexural strength is decreased because the strain-to-failure of the carbon/epoxy composite is lower than that of the glass/epoxy composite, while the flexural modulus is independent of the loading direction.

\author{
Insert Figure 11
}

Figure 11: Flexural strengths from experiments, FEA, and CLT for composites reinforced by IM-7 carbon and E glass fibres. Left: glass/epoxy laminas placed on the compressive face; right: glass/epoxy laminas placed on the tensile face 


\section{Insert Figure 12}

Figure 12: Flexural strengths from experiments, FEA, and CLT for composites reinforced by TR50S carbon and E glass fibres. Left: glass/epoxy laminas placed on the compressive face; right: glass/epoxy laminas placed on the tensile face

For the unidirectional hybrid composites, it is shown $[7,9]$ that the highest improvement in the flexural strength occurs when the volume fractions of the carbon/epoxy and glass/epoxy laminas were chosen to be $50 \%$ and $70 \%$, respectively. When glass fibres were placed on the compressive face, simulation was conducted with the hybrid ratio being varied between 0 (full carbon composite) and 1 (full glass composite). The flexural strengths and hybrid effects of the IM-7/E glass hybrid composites are shown in Figure 13.

\section{Insert Figure 13}

Figure 13: Flexural strengths (left) and hybrid effects (right) of IM-7/E glass hybrid composites when $V_{f c}=50 \%$ and $V_{f g}=\mathbf{7 0 \%}$

It is shown from Figure 13 that when a small amount of glass fibres are on the compressive face, the flexural strength is improved. The flexural strength increases with hybrid ratio when the hybrid ratio is between 0 and 0.375 . The maximum flexural strength is $1661 \mathrm{MPa}$ and occurs at hybrid ratio 0.375 . Compared to the full carbon composites, the strength increase is $20 \%$. If the flexural loading is reversed, i.e. glass fibres are place on the tensile face, the flexural strength decreases with increasing hybrid ratio. Compared to the full carbon composites, the flexural strength reduction is less than $20 \%$. When glass fibres are on the compressive face, positive hybrid effects are found. The maximum hybrid effect is $29.01 \%$ and occurs at hybrid ratio 0.375 . When glass fibres are on the tensile face, negative hybrid effects are found. 
The simulation was repeated when equal amounts of glass fibres were placed on both the compressive and tensile faces, i.e. sandwich type hybrid composites. The flexural strengths and hybrid effects are shown in Figure 14. It is shown contrary to the aforementioned stacking sequences, the flexural strength of the sandwich hybrid composite remains unchanged compared to the full carbon/epoxy composite when glass fibres are used as the core material.

\section{Insert Figure 14}

Figure 14: Flexural strengths and hybrid effects of IM-7/E glass sandwich hybrid composites when $V_{f c}=50 \%$ and $V_{f g}=70 \%$

The flexural strengths and hybrid effects of the hybrid sandwich composites reinforced by E glass and T300 carbon woven fabrics from a previous study [28] are shown in Figure 15. It is shown that positive hybrid effects exist for the two hybrid configurations. Compared to the full carbon laminate, $\left[\mathrm{C}_{2} \mathrm{G}_{2}\right]_{\mathrm{s}}$ retains much of the flexural strength while reduces the cost with half of the laminas being glass/epoxy.

Insert Figure 15

Figure 15: Flexural strengths (left) and hybrid effects (right) of the hybrid sandwich composites reinforced by $E$ glass and $\mathbf{T} 300$ carbon woven fabrics

\subsection{Strain Energy Density}

The strain energy densities of the IM-7/E glass hybrid composites from the experiments, FEA and CLT are shown in Figure 16. It is shown the full glass composites have higher toughness than the full carbon composites. When the glass fibres were placed on the compressive face, the hybrid composites showed improved toughness compared to the full carbon composites. Conversely, when the glass fibres were placed on the tensile face, the hybrid composites showed no improvement in the toughness. 
Insert Figure 16

Figure 16: Strain energy densities from experiments, FEA, and CLT for composites reinforced by IM-7 carbon and $\mathbf{E}$ glass fibres. Left: glass/epoxy laminas placed on the compressive face; right: glass/epoxy laminas placed on the tensile face

\section{Conclusions}

The flexural properties of carbon and glass fibre reinforced epoxy hybrid composites were studied. Both glass/carbon and sandwich stacking sequences were investigated. From both the experimental and simulation results the following conclusions can be drawn: For the unidirectional composites, when glass/epoxy laminas are placed on the compressive face, positive hybrid effects are present, and when glass/epoxy laminas are placed on the tensile face, the hybrid effect is dominantly negative. For the sandwich type hybrid composites, carbon/epoxy laminas should be the skin and glass/epoxy laminas should be the core.

\section{Statement of Conflicts of Interest}

There are no conflicts of interest.

\section{References}

1. Kretsis, G., A review on the tensile, compressive, flexural and shear properties of hybrid fibre-reinforced plastics. Composites, 1987. 18(1): p. 13-23.

2. $\quad$ Manders, P.W. and M.G. Bader, The strength of hybrid glass/carbon fibre composites. Journal of Materials Science, 1981. 16(8): p. 2233-2245.

3. Dong, C., J. Duong, and I.J. Davies, Flexural properties of S-2 glass and TR30S carbon fiber-reinforced epoxy hybrid composites. Polymer Composites, 2012. 33(5): p. 773-781.

4. Dong, C., H.A. Ranaweera-Jayawardena, and I.J. Davies, Flexural properties of hybrid composites reinforced by $S-2$ glass and T700S carbon fibres. Composites Part B: Engineering, 2012. 43(2): p. 573-581.

5. Sudarisman, B. de San Miguel, and I.J. Davies, The effect of partial substitution of E-glass fibre for carbon fibre on the mechanical properties of CFRP composites, in Proceedings of the International Conference on Materials and Metallurgical Technology 2009 (ICOMMET 2009). 2009. p. 125-128. 
6. Fischer, S. and G. Marom, The flexural behaviour of aramid fibre hybrid composite materials. Composites Science and Technology, 1987. 28(4): p. 291-314.

7. Dong, C. and I.J. Davies, Optimal design for the flexural behaviour of glass and carbon fibre reinforced polymer hybrid composites. Materials \& Design, 2012. 37: p. 450-457.

8. Dong, C. and I.J. Davies, Flexural properties of glass and carbon fiber reinforced epoxy hybrid composites. Proceedings of the Institution of Mechanical Engineers, Part L: Journal of Materials Design and Applications, 2013. 227(4): p. 308-317.

9. Dong, C. and I.J. Davies, Flexural and tensile strengths of unidirectional hybrid epoxy composites reinforced by $S-2$ glass and T700S carbon fibres. Materials \& Design, 2014. 54: p. 955-966.

10. Dong, C. and I.J. Davies, Flexural and tensile moduli of unidirectional hybrid epoxy composites reinforced by $S$-2 glass and T700S carbon fibres. Materials \& Design, 2014. 54: p. 893-899.

11. Dong, C. and I.J. Davies, Flexural strength of bidirectional hybrid epoxy composites reinforced by E glass and T700S carbon fibres. Composites Part B: Engineering, 2015. 72: p. 65-71.

12. Dong, C., Sudarisman, and I.J. Davies, Flexural properties of E glass and TR50S carbon fiber reinforced epoxy hybrid composites. Journal of materials engineering and performance, 2013. 22(1): p. 41-49.

13. Marom, G., et al., Hybrid effects in composites: conditions for positive or negative effects versus rule-of-mixtures behaviour. Journal of Materials Science, 1978. 13(7): p. 1419-1426.

14. Pandya, K.S., C. Veerraju, and N.K. Naik, Hybrid composites made of carbon and glass woven fabrics under quasi-static loading. Materials \& Design, 2011. 32(7): p. 4094-4099.

15. Giancaspro, J.W., C.G. Papakonstantinou, and P.N. Balaguru, Flexural Response of Inorganic Hybrid Composites With E-Glass and Carbon Fibers. Journal of Engineering Materials and Technology, 2010. 132(2): p. 021005-021005-8.

16. Muñoz, R., et al., Mechanical behavior and failure micromechanisms of hybrid 3D woven composites in tension. Composites Part A: Applied Science and Manufacturing, 2014. 59: p. 93-104.

17. Yu, H., et al., Pseudo-ductility in intermingled carbon/glass hybrid composites with highly aligned discontinuous fibres. Composites Part A: Applied Science and Manufacturing, 2015. 73: p. 35-44.

18. Miwa, M. and N. Horiba, Effects of fibre length on tensile strength of carbon/glass fibre hybrid composites. Journal of Materials Science, 1994. 29(4): p. 973-977.

19. Dorigato, A. and A. Pegoretti, Flexural and impact behaviour of carbon/basalt fibers hybrid laminates. Journal of Composite Materials, 2014. 48(9): p. 1121-1130.

20. Valença, S.L., et al., Evaluation of the mechanical behavior of epoxy composite reinforced with Kevlar plain fabric and glass/Kevlar hybrid fabric. Composites Part B: Engineering, 2015. 70: p. 1-8.

21. Ary Subagia, I.D.G., et al., Effect of stacking sequence on the flexural properties of hybrid composites reinforced with carbon and basalt fibers. Composites Part B: Engineering, 2014. 58: p. 251-258.

22. Swolfs, Y., et al., Tensile behaviour of intralayer hybrid composites of carbon fibre and self-reinforced polypropylene. Composites Part A: Applied Science and Manufacturing, 2014. 59: p. 78-84.

23. Taketa, I., et al., Interply hybrid composites with carbon fiber reinforced polypropylene and self-reinforced polypropylene. Composites Part A: Applied Science and Manufacturing, 2010. 41(8): p. 927-932.

24. Herakovich, C.T., On the Relationship between Engineering Properties and Delamination of Composite Materials. Journal of Composite Materials, 1981. 15(4): p. 336-348.

25. Pagano, N.J. and R.B. Pipes, The Influence of Stacking Sequence on Laminate Strength. Journal of Composite Materials, 1971. 5(1): p. 50-57. 
26. Kalantari, M., C. Dong, and I.J. Davies, Numerical investigation of the hybridisation mechanism in fibre reinforced hybrid composites subjected to flexural load. Composites Part B: Engineering, 2016. 102: p. 100-111.

27. Jalalvand, M., G. Czél, and M.R. Wisnom, Numerical modelling of the damage modes in UD thin carbon/glass hybrid laminates. Composites Science and Technology, 2014. 94: p. 39-47.

28. Zhang, J., et al., Hybrid composite laminates reinforced with glass/carbon woven fabrics for lightweight load bearing structures. Materials \& Design, 2012. 36: p. 75-80.

29. Bilyeu, B., W. Brostow, and K.P. Menard, Epoxy thermosets and their applications I: chemical structures and applications. Journal of Materials Education, 1999. 21(5/6): p. 281286.

30. Mallick, P.K., Fiber-Reinforced Composites: Materials, Manufacturing, and Design. 2nd ed. 1993, New York: Marcel Dekker.

31. Xiao, X., V. Astakhov, and T. Su. A study of resin transfer molding process using experimental design method. in Proceedings of ICCM-12. 1999. Paris, France.

32. Sudarisman and I.J. Davies, The effects of processing parameters on the flexural properties of unidirectional carbon fibre-reinforced polymer (CFRP) composites. Material Science and Engineering: A, 2008. 498(1-2): p. 65-68.

33. ASTM International, Standard test method for flexural properties of polymer matrix composite materials, in ASTM D7264/D7264M-15. 2015, ASTM International: West Conshohocken.

34. Czél, G. and M.R. Wisnom, Demonstration of pseudo-ductility in high performance glass/epoxy composites by hybridisation with thin-ply carbon prepreg. Composites Part A: Applied Science and Manufacturing, 2013. 52: p. 23-30.

35. Chou, T.-W., Microstructural Design of Fiber Composites. 1992, Cambridge, U.K.: Cambridge University Press.

36. Hashin, Z., Analysis of composite materials - a survey. Journal of Applied Mechanics, 1983. 50(3): p. 481-505.

37. Lo, K.H. and E.S.M. Chim, Compressive strength of unidirectional composites. Journal of Reinforced Plastics and Composites, 1992. 11(8): p. 838-896.

38. Budiansky, B. and N.A. Fleck, Compressive failure of fibre composites. Journal of the Mechanics and Physics of Solids, 1993. 41(1): p. 183-211.

39. Bullock, R.E., Strength ratios of composite materials in flexure and in tension. Journal of Composite Materials, 1974. 8: p. 200-206. 